\title{
FUNCTIONAL RECOVERY IN PATIENTS WITH POST-TRAUMATIC SPINAL CORD INJURIES: AN OUTCOME OF GROSS MOBILITY AT PARAPLEGIC CENTER PESHAWAR, PAKISTAN
}

\section{Amir Zeb', Aatik Arsh ${ }^{2}$, Sher Bahadur ${ }^{3}$, Inayat Shah $^{4}$, Syed Muhammad Ilyas ${ }^{5}$}

\begin{abstract}
OBJECTIVE: To determine the outcomes of gross mobility after physical therapy interventions undertaken at the Paraplegic Center Peshawar, Khyber Pakhtunkhwa, Pakistan for functional recovery of patients with spinal cord injuries $(\mathrm{SCl})$.

METHODS: This sequential intervention trial was conducted from June 2016 to July 2017, at Paraplegic Center Peshawar, Khyber Pakhtunkhwa, Pakistan. Using consecutive sampling technique, a total of 76 persons with paraplegia were included. Persons with tetraplegia were excluded. Motor relearning program (MRP) was applied three hours per day in a standardized intervention, 3 days per week. The post intervention evaluation was done by using spinal cord independence measure (SCIM) scale. Data was analyzed in SPSS version 20.0, where the mean score of post intervention (for each six visits) was compared to see the improvement. ANOVA was used and a p value of $<0.05$ was considered significant.
\end{abstract}

RESULTS: Out of 76 patients with spinal cord injuries, 19 (25\%) were females and $57(75 \%)$ were males. There was a gradual increase in the improvement of gross mobility of persons with $\mathrm{SCl}$ as a result of physical therapy interventions based on MRP. Mean scores for mobility in bed and action to prevent pressure sores, bed-wheelchair transfers: wheelchair-toilet-tub, indoors and outdoors mobility, mobility for moderate distances ( $10-100$ meters), outdoors mobility (> 100 meters), wheelchair-car transfer \& ground-wheelchair transfers showed significant improvement $(p<0.01)$ during six visits. However, no significant improvement was observed in stair management $(p=0.13)$.

CONCLUSION: Physical therapy based on a MRP is an effective tool for improvement of gross mobility in persons with $\mathrm{SCl}$.

KEY WORDS: Physical therapy (Non-MeSH); Physiotherapy (MeSH); Rehabilitation (MeSH); Physical Therapy Modalities (MeSH); Spinal Cord Injuries (MeSH); Mobility (Non-MeSH); Mobility Limitation (MeSH); Motor relearning program (Non-MeSH); Spinal cord independence measure scale (Non-MeSH).

THIS ARTICLE MAY BE CITED AS: Zeb A, Arsh A, Bahadur S, Shah I, llyas SM. Functional recovery in patients with post-traumatic spinal cord injuries: an outcome of gross mobility at Paraplegic Center Peshawar, Pakistan. Khyber Med Univ J 2019; I ( I):I7-20. DOI: 10.35845/kmuj.2019.18442.

\section{INTRODUCTION}

$S^{p}$ inal cord injury $(\mathrm{SCl})$ is one of the major causes of lifelong disability in both developing and developed countries.' The most obvious consequences of $\mathrm{SCl}$ are paralysis. However, it has widespread effects on many body functions including bowel and bladder, respiratory, cardiovascular and sexual dysfunctions. It has social, financial and psychological implications
I Senior Physical Therapist, Physiotherapy Department, Paraplegic Center Peshawar, Pakistan

2 Physical Therapist, Physiotherapy Department, Paraplegic Center Peshawar, Pakistan

3 Senior Research Officer, Department of Medical Research, Rehman Medical College, Peshawar, Pakistan

4 Trainee Medical Officer, Department of Neurosurgery, Medical Teaching Institute Lady Reading Hospital, Peshawar, Pakistan

5 Chief Executive Officer, Paraplegic Center Peshawar, Pakistan

Email『: aatikarshkmu@yahoo.com

Date Submitted: June 12,2018

Date Revised: March 21, 2019

Date Accepted: $\quad$ March 21,2019

while it tends to increases individual's susceptibility to other secondary complications like pressure sores, latelife renal failures, musculoskeletal deformities, neuropathic pains, osteoporosis and heterotrophic ossifications etc. $^{2,3}$

In Pakistan, the population based data on $\mathrm{SCl}$ is not available; however few single-center based retrospective studies reported demographic information of $\mathrm{SCl}$ patients in Pakistan. ${ }^{4-7}$ The primary goal of rehabilitation of $\mathrm{SCl}$ patients is to maximize functional independence and minimize dependency. ${ }^{8}$ Interdisciplinary team comprising of physiatrists, physical therapists, nurses, occupational therapists, psychologists and social workers work in collaboration to maximize functional independence.

Mobility tasks such as bed mobility training (mat activities e.g. rolling, prone on elbow, prone on hands, supine on elbows, sitting in bed, vertical lift), transfers training (e.g. transfers to and from bed, floor, commode chair and car etc.) balance training, co-ordination training and gait training are applied in order to achieve functional goals. ${ }^{10}$ These activities, not only enable $\mathrm{SCl}$ patients to live a dignified life but also help in preventing secondary complications associated with SCI. '"

Although previous research studies reported significant improvements in $\mathrm{SCl}$ patients who underwent standard rehabilitation program and mobility training, yet evidence regarding efficacy of motor tasks training is 
FUNCTIONAL RECOVERY IN PATIENTS WITH POST-TRAUMATIC SPINAL CORD INJURIES: AN OUTCOME OF GROSS MOBILITY AT PARAPLEGIC CENTER PESHAWAR, PAKISTAN

TABLE I: COMPARISON OF GROSS MOBILITY AMONG PATIENTS WITH SPINAL INJURIES WITH RESPECT TO CONSECUTIVE FOLLOW UP FOR REHABILITATION SERVICES

\begin{tabular}{|c|c|c|c|c|c|c|c|}
\hline $\begin{array}{l}\text { Outcome Variables } \\
\text { of Rehabilitative } \\
\text { Interventions }\end{array}$ & $\begin{array}{l}\text { Mean Score } \\
\text { at I }{ }^{\text {st }} \text { Visit } \\
t(\bar{x} \pm \text { S.D })\end{array}$ & $\begin{array}{l}\text { Mean Score } \\
\text { at } 2^{\text {nd }} \text { Visit } \\
t(\bar{x} \pm \text { S.D })\end{array}$ & $\begin{array}{l}\text { Mean Score } \\
\text { at } 3^{\text {rd }} \text { Visit } \\
t(\bar{x} \pm S . D)\end{array}$ & $\begin{array}{l}\text { Mean Score } \\
\text { at } 4^{\text {th }} \text { Visit } \\
t(\bar{x} \pm \text { S.D })\end{array}$ & $\begin{array}{c}\text { Mean Score } \\
\text { at } 5^{\text {th }} \text { Visit } \\
t(\bar{x} \pm S . D)\end{array}$ & $\begin{array}{l}\text { Mean Score } \\
\text { at } 6^{\text {th }} \text { Visit } \\
t(\bar{x} \pm \text { S.D })\end{array}$ & $\begin{array}{c}\text { P- } \\
\text { Value }\end{array}$ \\
\hline $\begin{array}{l}\text { Mobility in Bed and } \\
\text { Action to Prevent } \\
\text { Pressure Sores }\end{array}$ & $0.80 \pm 1.8$ & $2.3 \pm 2.5$ & $2.4 \pm 2.6$ & $6.6 \pm 2.6$ & $2.5 \pm 2.4$ & $4.6 \pm 1.8$ & 0.0001 \\
\hline $\begin{array}{l}\text { Transfers } \\
\text { (bed-wheelchair) }\end{array}$ & $0.24 \pm 0.6$ & $0.64 \pm 0.8$ & $1.0 \pm 1.3$ & $0.76 \pm 1.1$ & $4.2 \pm 1.0$ & $4.1 \pm 2.0$ & 0.0001 \\
\hline $\begin{array}{l}\text { Transfers } \\
\text { (wheelchair-toilet-tub) }\end{array}$ & $0.2 \pm 0.6$ & $0.7 \pm 0.8$ & $0.7 \pm 0.8$ & $1.5 \pm 0.8$ & $2.3 \pm 0.5$ & $3.2 \pm 0.5$ & 0.0001 \\
\hline $\begin{array}{l}\text { Mobility Indoors and } \\
\text { Outdoors }\end{array}$ & $0.3 \pm 0.9$ & $1.5 \pm 2.0$ & $1.5 \pm 1.8$ & $2.1 \pm 1.3$ & $2.4 \pm 1.2$ & $3.1 \pm 1.0$ & 0.0001 \\
\hline $\begin{array}{l}\text { Mobility for Moderate } \\
\text { Distances (10-100 } \\
\text { meters) }\end{array}$ & $0.4 \pm 1.1$ & $1.4 \pm 1.9$ & $1.4 \pm 1.6$ & $1.0 \pm 1.5$ & $0.5 \pm 1.1$ & $0.3 \pm 0.9$ & 0.0001 \\
\hline $\begin{array}{l}\text { Mobility Outdoors } \\
\text { (more than } 100 \text { meters) }\end{array}$ & $0.3 \pm 0.8$ & $1.3 \pm 1.8$ & $1.2 \pm 1.5$ & $1.7 \pm 1.4$ & $2.1 \pm 1.2$ & $3.1 \pm 0.5$ & 0.0001 \\
\hline Stair Management & $0.04 \pm 0.2$ & $0.2 \pm 0.5$ & $0.2 \pm 0.8$ & $0.08 \pm 0.3$ & $0.09 \pm 0.4$ & $0.03 \pm 0.2$ & 0.13 \\
\hline $\begin{array}{l}\text { Transfers } \\
\text { (ground-wheelchair) }\end{array}$ & $0.2 \pm 0.4$ & $0.6 \pm 1.0$ & $0.5 \pm 0.7$ & $0.6 \pm 0.9$ & $1.2 \pm 0.5$ & $1.7 \pm 0.4$ & 0.001 \\
\hline $\begin{array}{l}\text { Transfers } \\
\text { (wheelchair-car) }\end{array}$ & $0.05 \pm 0.2$ & $0.2 \pm 0.3$ & $0.3 \pm 0.7$ & $0.6 \pm 0.7$ & $0.8 \pm 0.2$ & $1.07 \pm 0.2$ & 0.002 \\
\hline
\end{tabular}

controversial. ${ }^{12-14}$ Therefore this study was designed to determine the outcomes of gross motility after series of physical therapy interventions based on motor relearning program (MRP) among $\mathrm{SCl}$ patients.

\section{METHODS}

This was an experimental study based on sequential intervention of MRP for three hours per day in a standardized intervention of 3 days per week. The study was conducted in Paraplegic Centre, Peshawar, Pakistan from June 2016 to July 2017.

Patients with paraplegia regardless of their gender, area of living and causes of injuries were included while tetraplegic and $\mathrm{SCl}$ patient with complications and/or other co-morbidities were excluded to minimize confounding. Using consecutive sampling technique, a total of 76 registered patients participated in the study. Informed consent was taken from all patients. Ethical approval was obtained from Institutional Ethical Review Committee of Paraplegic Center, Peshawar.

The subjects underwent bed mobility training (mat activities e.g. rolling, prone on elbow, prone on hands, supine on elbows, sitting in bed, vertical lift), transfers training (e.g. transfers to and from bed, floor, commode chair and car etc.) and gait training for one month. The outcomes of interventions were evaluated using spinal cord independence measure (SCIM) scale. Trained physical therapists were involved in pre and post intervention assessment. Data was analyzed in SPSS version 20.0, where the mean score of post intervention (for each 6 visits) was compared to see the improvement. ANOVA test was used and a $p$ value $<0.05$ was considered significant.

\section{RESULTS}

A total of 76 persons with $\mathrm{SCl}$ participated in the present study in which $19(25.0 \%)$ were female and 57 $(75.0 \%)$ were male. Educational status of the participants shows that most of them $(n=28 ; 36.8 \%)$ were uneducated followed by 27 (35.5\%) with 6-7 years of education, 13 (17.1\%) had below primary education while 8 ( $10.5 \%)$ had secondary school level education.

Majority of patients $(n=57 ; 75 \%)$ were married while remaining 19 (25\%) were unmarried. Patients were presented from both rural $(n=40$; $52.6 \%)$ and urban $(n=36 ; 47.4 \%)$ areas. Forty-eight (63.1\%) patients had chronic $\mathrm{SCl}$ (more than 42 days of $\mathrm{SCl}$ ) while $28(36.9 \%)$ were acute (less than 42 days of SCl) cases. Forty-nine (49; $35.5 \%$ ) of them underwent spine fixation procedure.

There was a gradual increase in the improvement of gross mobility of persons with $\mathrm{SCl}$ as a result of physical therapy interventions based on MRP. The mean score of gross mobility at consecutive visits (follow-up) is given in Table I. The $p$ value for consecutive mean difference in majority of variables was highly significant $(p<0.001)$. There was non-significant improvement regarding stair management $(p=0.130)$.

\section{DISCUSSION}

$\mathrm{SCl}$ affects mental, physical, social and psychological aspects of life. The outcomes of interventions for rehabilitation of patients with $\mathrm{SCl}$ are mostly measured in terms of gross mobility. ${ }^{15}$ In the present study the gross mobility among patients with $\mathrm{SCl}$ was assessed in consecutive follow up visits. The outcome of gross mobility was measured in terms of; mobility in bed, 
transfers from bed to wheel chair and wheel chair to toilet or tub, wheel chair to car and ground. It also includes indoor and outdoor mobility and stair management. There was a gradual increase in the improvement of gross mobility of persons with $\mathrm{SCl}$ as a result of physical therapy interventions based on MRP.

The goal of physical rehabilitation is to maximize functional independence and mobility. Previous studies reported that comprehensive rehabilitation improves gross mobility in $\mathrm{SCl}$ patients. ${ }^{16}$ Current study also reported that physical rehabilitation interventions could improve bed mobility, transfers and indoor and outdoor mobility. Though $\mathrm{SCl}$ is incurable but rehabilitation strategies aim to minimize complications and maximize independence according to patient functional capabilities. $^{17,18}$

Conventionally, the physical rehabilitation interventions have been considered to improve functional outcomes in $\mathrm{SCl}$ patients only through enhancement, compensation and replacement of the remaining function of nerve and muscle. ${ }^{10}$ However, recently accumulating evidences indicated that physical rehabilitation interventions can improve the function in different levels from end-effectors organ such as skeletal muscle to cerebral cortex through reshaping skeletal muscle structure and muscle fiber type, regulating physiological and metabolic function of motor neurons in the spinal cord and remodeling function of the cerebral cortex. ${ }^{19}$

Physical rehabilitation interventions including bed mobility training and transfer training etc enable $\mathrm{SCl}$ patients to live a dignified life. Despite the fact that a growing number of studies from developed countries reported effectiveness of physical trainings in the rehabilitation of $\mathrm{SCl}$ patients, however literature from developing countries is scarce. ${ }^{20,21}$ The results of present study indicate significant improvement, which could be augmented as a result of integrative rehabilitation services provided at Paraplegic Center, Peshawar. Despite the fact that current study was a preliminary study to determine effectiveness of physical therapy training for spinal cord injury patients however current study has some limitations. First, sample size of current study was small due to which results of current study cannot be generalized. Secondly, due to lack of control group, confounding variables were difficult to minimize. Moreover, current study was conducted in a single rehabilitation center and multicenter, large clinical trials are recommended in future.

\section{CONCLUSION}

Physical therapy based on a MRP is an effective tool for improvement of gross mobility in persons with SCls. It is recommended that principles of motor relearning should be implemented in all $\mathrm{SCl}$ rehabilitation centers.

\section{REFERENCES}

I. Chen Y, Tang Y, Vogel L, DeVivo M. Causes of spinal cord injury. Top Spinal Cord Inj Rehabil 2013;19(I):I-8. DOI:10.1310/ scil90I-I.

2. Ma VY, Chan L, Carruthers KJ. Incidence, prevalence, costs, and impact on disability of common conditions requiring rehabilitation in the United States: stroke, spinal cord injury, traumatic brain injury, multiple sclerosis, osteoarthritis, rheumatoid arthritis, limb loss, and back pain. Arch Phys Med Rehabil 2014;95(5):986-95. DOI:10.1016/ j.apmr.2013.10.032.

3. Harvey LA. Physiotherapy rehabilitation for people with spinal cord injuries. J Physiother 2015;62 (I):4-II. DOI:I0.1016/j.jphys. 20I5.II.004.

4. Arsh A, Darain H, Haq ZU, Zeb A, Ali I, llyas SM. Epidemiology of spinal cord injuries due to bomb blast attacks, managed at Paraplegic Centre Peshawar, Pakistan: a nine years retrospective study. Khyber Med Univ J 20I 7;9(2):55-9.

5. Arsh A, Darain H, llyas SM. Epidemiology and prevalence of deep venous thrombosis in patients with spinal cord injury. Pak J Neurological Sci 20 I 6; I I (4):22-5.

6. Arsh A, Darain H, llyas SM, Zeb A. Prevelacne of pressure ulcers in patients with spinal cord injury; a retrospective study. Pak J Neurological Sci 20 I 2; I I (4): I6-2 I.

7. Arsh A, Darain H, Muhammad D, Khan MN, llyas SM, Zeb A, et al. Factors responsible for readmissions to rehabilitation center following spinal cord injury. J Khyber Coll Dent 20 I 7;7(2):60-5.

8. McKinley WO, Seel RT, Gadi RK, Tewksbury MA. Nontraumatic vs. traumatic spinal cord injury: a rehabilitation outcome comparison. Am J Phys Med Rehabil 2001;80 (9):693-9. DOI: I0. I3 I0/scil 90 I-I.

9. Brown D, Cameron T, Donoghue F, McKinstry A, Sweeney J, Burt S, et al. Outcomes of patients with spinal cord injury before and after introduction of an interdisciplinary tracheostomy team. Crit Care Resusc 2009; I I (I): 14-9.

10. Harvey L. Management of spinal cord injuries: a guide for physiotherapists. I $^{\text {st }}$ edition. 2008. Churchill Livingstone, London.

II.Dijkers MP. Quality of life of individuals with spinal cord injury: $A$ review of conceptualization, measurement, and research findings. J Rehabil Res Dev 2005;42(3):87-II0. DOI:10.1682/ JRRD.2004.08.0100.

12. Bedbrook GM. The care and management of spinal cord injuries. $\mathrm{I}^{\text {st }}$ edition. 198I Springer-Verlag, New York.

13. Dobkin $\mathrm{BH}$. Motor rehabilitation after stroke, traumatic brain, and spinal cord injury: common denominators within recent clinical trials. Curr Opin Neurol 2009;22(6) :563-9. DOI: I0.1097/WCO. 0b0 I 3e32833।4bll.

14. Spooren AI, Janssen-Potten YJ, Kerckhofs E, Seelen HA. Outcome of motor training programmes on arm and hand functioning in patients with cervical spinal cord injury according to different levels of the ICF: a systematic review. J Rehabil Med 2009;4I (7):497-505. DOI: 10.2340/16501977-0387.

15. Nas K, Yazmalar L, Sah V, Aydin A, Ones K. Rehabilitation of spinal cord injuries. World J Orthop 2015; 6(I) :8-I6. DOI: 10.53I2/wjo.v6.il.8. 
16. Simpson LA, Eng JJ, Hsieh JT, Wolfe DL, Spinal Cord Injury Rehabilitation Evidence Research Team. The health and life priorities of individuals with spinal cord injury: a systematic review. J Neurotrauma 20I2;29(8): I548-55. DOI: 10.1089/ neu.2011.2226.

17. Hatem SM, Saussez G, Della Faille $M$, Prist $V$, Zhang $X$, Dispa $D$, et al. Rehabilitation of Motor Function after Stroke: A Multiple Systematic Review Focused on Techniques to Stimulate Upper Extremity Recovery. Front Hum Neurosci 2016;10: 442. DOI:10.3389/ fnhum.2016.00442.

18. PollockA, Baer G, Campbell P, Choo $\mathrm{PL}$, Forster A, Morris J, et al. Physical rehabilitation approaches for the recovery of function and mobility following stroke. Cochrane Database Syst Rev 2014;4: CD001920.DOI: |0.1002/ |465 I858. CD00 I920. pub3.

19. Fu J, Wang H, Deng L, Li J. Exercise training promotes functional recovery after spinal cord injury. Neural Plast 2016;2016:4039580. DOI: I0.I I55/20I6/4039580.

20. Darain H, Arsh A, Zeb A, llyas SM,
Muhammad D, Khan MN Epidemiology, clinical features and consequences of spinal cord injury in children. J Coll Physicians Surg Pak 20I8;28(7):532-5. DOI: |0.2927|/jcpsp.20|8.07.532.

21. Zeb A, Arsh A, Bahadur S, llyas SM. Effectiveness of transcutaneous electrical nerve stimulation in management of neuropathic pain in patients with post traumatic incomplete spinal cord injuries. Pak Med Sci 2018;34(5):II77-80. DOI: I0.12669/pjms.345. I 5659 .

\section{AUTHORS' CONTRIBUTIONS}

Following authors have made substantial contributions to the manuscript as under:

AZ: Acquisition, analysis \& interpretation of data, drafting the manuscript, final approval of the version to be published

AA: Concept \& study design, acquisition of data, critical review, final approval of the version to be published

SB, IS \& SMI: Acquisition of data, critical review, final approval of the version to be published

Authors agree to be accountable for all aspects of the work in ensuring that questions related to the accuracy or integrity of any part of the work are appropriately investigated and resolved.

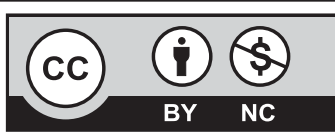

This is an Open Access article distributed under the terms of the Creative Commons Attribution-Non Commercial 2.0 Generic License.

KMUJ web address: www.kmuj.kmu.edu.pk Email address: kmuj@kmu.edu.pk 